\title{
Fluticasone furoate nasal spray in the treatment of allergic rhinitis
}

\author{
Pedro Giavina-Bianchi' \\ Rosana Agondi' \\ Rafael Stelmach ${ }^{2}$ \\ Alberto Cukier ${ }^{2}$ \\ Jorge Kalil' \\ 'Division of Clinical Immunology and \\ Allergy, University of São Paulo, São \\ Paulo, Brazil; 'Pulmonary Division, \\ University of São Paulo, São Paulo, \\ Brazil
}

\begin{abstract}
Allergic rhinitis (AR) is a prevalent disease with great morbidity and significant societal and economic burden. Intranasal corticosteroids are recommended as first-line therapy for patients with moderate-to-severe disease, especially when nasal congestion is a major component of symptoms. To compare the efficacy and safety profile of different available intranasal corticosteroids for the treatment of AR, it is important to understand their different structures and pharmacokinetic and pharmacodynamic properties. Knowledge of these drugs has increased tremendously over the last decade. Studies have elucidated mechanisms of action, pharmacologic properties, and the clinical impact of these drugs in allergic respiratory diseases. Although the existing intranasal corticosteroids are already highly efficient, the introduction of further improved formulations with a better efficacy/ safety profile is always desired. Fluticasone furoate nasal spray is a new topical corticosteroid, with enhanced-affinity and a unique side-actuated delivery device. As it has high topical potency and low potential for systemic effects, it is a good candidate for rhinitis treatment.
\end{abstract}

Keywords: fluticasone furoate, corticosteroids, rhinitis, efficacy, safety, ARIA

\section{Allergic rhinitis}

Allergic rhinitis (AR) is an inflammatory disease of nasal mucosa induced by an IgEmediated immune response. It is clinically defined as a symptomatic condition with four major symptoms: rhinorrhea, sneezing, nasal itching and obstruction (International Rhinitis Management Working Group 1994; Bousquet et al 2001).

Patients with AR can also experience fatigue, sleep disturbance, social function impairment, depressed mood, anxiety, learning and attention impairment, increased work or school absenteeism, and decreased work or school performance and productivity. The impact is made worse because of co-morbidities such as sinusitis, otitis media with effusion, allergic conjunctivitis, bronchial asthma, and dental disorders. Therefore, AR has a high morbidity with significant societal and economic burden, due to direct and indirect costs (International Rhinitis Management Working Group 1994; Yawn et al 1999; Crystal-Peters et al 2000; Leynaert et al 2000a; Bousquet et al 2001; O'Connell 2004; Schoenwetter et al 2004).

AR has an estimated prevalence of $30 \%$ of the general population, which has been increasing, particularly in Western countries (The International Study of Asthma and Allergies I Childhood - ISAAC - Steering committee 1998; Upton et al 2000; Bousquet et al 2001). It is the most common chronic disorder in children and can be considered a major public health problem.

\section{Allergic rhinitis and its impact on asthma}

The ARIA (Allergic Rhinitis and its Impact on Asthma) guideline was published in 2001, bringing some conceptual changes for rhinitis, such as the modification of its classification, and emphasizing the relationships between upper and lower airways (Figure 1; Bousquet et al 2001). 
To establish a guideline, proposing a standardized management plan for allergic rhinitis.

To disseminate this guideline to general practitioners and specialist physicians.

To emphasize allergic rhinitis impact on asthma.

To institute a multi-professional forum to discuss about allergic respiratory diseases.

Figure I Allergic rhinitis and its impact on asthma (ARIA) aims.

AR can be classified as perennial or seasonal (hay fever), depending on the timing and type of allergen involved in triggering the allergy. Patients with seasonal AR experience symptomatic exacerbations primarily during pollen seasons. However, more recently, AR has also been classified as intermittent or persistent, according to symptoms duration and frequency. This classification also divides AR into mild or moderate/severe. Severity is measured as a short assessment of the impairment in the day-to-day life of the patient and not as a nasal symptom score (Bousquet et al 2001).

Nowadays, rhinitis and asthma are recognized as manifestations of one syndrome, the chronic allergic respiratory syndrome, also known as united airway disease. There is epidemiologic, immunopathologic, and clinical evidences that support an integrated view of these diseases and permit an understanding of their interactions (Leynaert et al 2000b; Bousquet et al 2001; Linneberg et al 2002; Togias 2003). Almost all patients with asthma have rhinitis and the presence of severe rhinitis in patients with asthma is associated with worse asthma outcomes. AR is a risk factor for asthma development. Besides, beneficial effects of nasal treatment on the lower airways have been reported, with fewer emergency service visits, fewer hospitalizations, and declining bronchial responsiveness (Crystal-Peters et al 2002; Taramarcaz 2003).

\section{Rhinitis treatment}

Rhinitis treatment includes allergen avoidance, pharmacotherapy, and immunotherapy. Intranasal corticosteroids (INS) are recommended as first-line therapy for patients with moderate-to-severe AR, especially when nasal congestion is a major component of symptoms (International Rhinitis Management Working Group 1994; Bousquet et al 2001; van Cauwenberge et al 2005; Antonicelli et al 2007). INSs improve nasal congestion more effectively and are more cost-effective than nonsedating antihistamines, the most commonly prescribed
AR medications (Craig et al 1998; Schoenwetter et al 2004; Price et al 2006). Oral antihistamines may be used concomitantly with INS in more severe cases, in rhinitis exacerbations, and in patients with ocular and skin symptoms that can occur, since atopic diseases are components of a systemic syndrome.

The major advantage of INS administration is that high concentrations of the drug, with rapid onset of action, can be delivered directly into the target organ, so that systemic effects are avoided or minimized. INS exert their antiinflammatory effect through the inhibition of the production of many different cytokines, chemokines, enzymes, and cell adhesion molecules, after their interaction with intracellular glucocorticoid receptors.

To compare the efficacy and safety profile of different available INS for the treatment of AR, it is important to understand the different structures and their pharmacokinetic and pharmacodynamic properties (Corren 1999; Hübner et al 2005). Pharmacokinetics are related to the concentration of a drug at the site of action over time, whereas pharmacodynamics relate to drug's concentration to its clinical effect. To determine the overall effect of a drug over time, a combination of pharmacokinetics/pharmacodynamics parameters has to be accomplished (Hübner et al 2005).

Receptor potency is a pharmacodynamic parameter and represents the binding ability of INS that is expressed by its receptor affinity compared with dexamethasone. Topical potencies of glucocorticoids have been most often compared with use of the Mckenzie assay, which assesses skin-blanching responses as a measure of cutaneous vasoconstriction (McKenzie 1962). Another recent method for comparing the biologic effects of topical corticosteroids has been to evaluate the inhibitory effects of various compounds on the production of $\mathrm{T}$ lymphocyte-derived cytokines (English et al 1994; Umland et al 1997).

Some important pharmacokinetic parameters are: prodrug design, organ deposition, onset of action, lipophilicity, bioavailability, systemic clearance, protein binding, volume of distribution, device of administration, and nasal residence time.

A Cochrane Systematic Review compared the efficacy and safety of fluticasone propionate (FP) with beclomethasone dipropionate and budesonide in the treatment of chronic asthma. FP-treated participants had slightly better lung function, but with increased hoarseness and, probably, with a higher risk of sore throat (Adams et al 2007).

It is important to emphasize that decisions on the use of INS, especially in children, should be guided by the 
physician's clinical experience and patients' individual circumstances and preferences (Al Sayyad et al 2007).

\section{Fluticasone furoate}

Fluticasone furoate (FF) is a new, topical, intranasal, enhanced-affinity trifluorinated glucocorticoid, with potent anti-inflamatory activity and low systemic exposure. FF is a synthetic fluorinated corticosteroid having the chemical name $(6 \alpha, 11 \beta, 16 \alpha, 17 \alpha)$-6,9-difluoro-17$\{[($ fluoro-methyl)thio]carbonyl\}-11-hydroxy-16-methyl-3oxoandrosta-1,4-dien-17-yl 2-furancarboxylate (Figure 2). The drug (GW685698X; Veramyst ${ }^{\mathrm{TM}}$; Avamys ${ }^{\mathrm{TM}}$ ) comes in a nasal spray, as an aqueous suspension of micronized fluticasone furoate for topical administration to the nasal mucosa by means of a metering, atomizing spray pump. Each actuation delivers $27.5 \mu \mathrm{g}$ of FF in a volume of $50 \mu \mathrm{L}$ of suspension that also contains $0.015 \% \mathrm{w} / \mathrm{w}$ benzalkonium chloride, dextrose anhydrous, edetate disodium, microcrystalline cellulose, carboxymethylcellulose sodium, polysorbate 80 , and purified water.

It has been developed for the treatment of AR in patients 2 years of age and older and is administered via a unique, side-actuated device. FF is administered once daily and its recommended starting dose is $55 \mu \mathrm{g}$ for children and $110 \mu \mathrm{g}$ for adults and adolescents (FDA 2007; GlaxoSmithKline 2007; McCormack and Scott 2007; RxList 2007).

\section{Pharmacodynamic profile}

Fluticasone furonate has high receptor affinity, with low equilibrium dissociation constant $\left(\mathrm{k}_{\mathrm{d}}=0.3 \mathrm{nmol} / \mathrm{L}\right)$ and with greater relative receptor affinity (2989) than mometasone furoate (2244), fluticasone propionate (1775), beclomethasone-17monopropionate (1345), ciclesonide active principle (1212), and budesonide (855) (Biggadike et al 2007).

Some in vitro studies showed that FF displayed greater potency than other corticosteroids in inhibiting tumor necrosis factor synthesis and action. It was also more

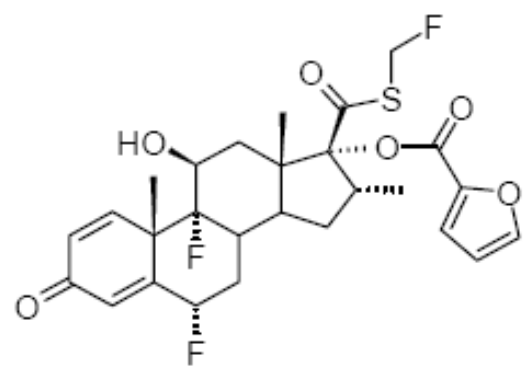

Figure 2 Fluticasone furoate chemical structure. potent in preventing damage to cultured human lung epithelial cells by different stimulus. Experimental studies demonstrated more potent and faster anti-inflammatory activity of FF than fluticasone propionate (Salter et al 2006, 2007).

FF displayed high selectivity for the glucocorticoid receptor in vitro and had no effect on the hypothalamicpituitary-adrenal (HPA) axis in children or adults during clinical trials (Pastel et al 2007; Salter et al 2007; Tripathy et al 2007). Laboratory tests that assess basal and dynamic function of HPA axis are frequently used to determine the systemic effects of INS.

\section{Pharmakokinetic profile}

After single- and multiple-dose intranasal administration, plasma fluticasone furoate concentrations are below the lower limit of quantification in most patients (Allen et al 2007; Hughes et al 2007; Martin 2007). One study showed that only $2 \%$ of samples from patients receiving $110 \mu \mathrm{g}$ of FF had quantifiable plasma drug concentrations (Martin 2007).

Systemic bioavailability is determined by the sum of 2 components, including the portion of the drug that is absorbed via the nasal mucosa plus the portion that is swallowed. The last one is the major route for circulation, what makes the first-pass hepatic metabolism after drug absorption in the gastrointestinal tract very important.

Intranasal FF $880 \mu \mathrm{g}$ was administered every 8 hours for 10 doses in healthy adult volunteers and the average absolute bioavailability was $0.5 \%$. Oral bioavailability after $2 \mathrm{mg}$ single oral dose is $1.26 \%$ and elimination half-life after single intravenous dose is 15.1 hours (FDA 2007; Allen et al 2007).

FF was $99.4 \%$ bound to plasma protein in vitro and other research indicated extensive first-pass metabolism of the absorbed drug (Salter et al 2006; Allen et al 2007). Protein binding is highly relevant because only the unbound free drug can exert an effect at the receptor site. As long as the corticosteroid is bound to a protein, it is unable to bind to its receptor. Clearance of FF is primarily by hydrolysis in the liver by the cytochrome P450 isozyme (CYP) 3A4 that converts the drug to the 17 [beta]-carboxylic acid metabolite (M10), which displays low glucocorticoid receptor agonist potency. The drug is excreted mainly in the feces, with only minor amounts in the urine (Hughes et al 2005; FDA 2007).

FF is a synthetic, lipophilic, corticosteroid (Biggadike et al 2006). Agents highly lipophilic will demonstrate a higher and 
faster rate of uptake by the nasal mucous membrane, a higher level of retention within the nasal tissue, and an enhanced ability to reach the glucocorticoid receptor.

It has become widely recognized that many patients use INS on an as-need basis only, stopping medication when symptoms substantially abate. In support of this approach are recent studies demonstrating that intermittent use of INS is moderately effective in many patients (Juniper et al 1993). Therefore, onset of action can become an important feature of these drugs. In a perennial AR clinical trial, a statistically significant difference between $\mathrm{FF}$ and placebo was first noted at 24 hours after the first dose for instantaneous total nasal symptom score and after 2 days for reflective total nasal symptom score (Vasar et al 2007).

\section{Drug formulation and delivery device}

Drug's formulation and delivery device may affect the efficacy, tolerability, drug retention and deposition in nasal tissue, safety and patient preference and adherence to treatment (Hübner et al 2005; Meltzer 2007). Optimization of formulation is one way to improve rhinitis treatment.

Additives and preservatives are included in INS formulations to prevent bacterial growth, confer both taste and smell, absorb extra water, and maintain appropriate moisture levels. Some of these agents may irritate or dry nasal tissue and/or, rarely, lead to hypersensitivity. There is benzalkonium chloride, polysorbate, and carboxymethylcellulose in the FF formulation.

Benzalkonium chloride is a cationic surfactant used as a preservative in nasal solutions. Studies have showed that it can induce nasal mucociliary dysfunction, nasal irritation and hypersecretion, burning sensation, degenerative changes in supportive and olfactory cells, and squamous cell metaplasia (Steinsvag et al 1996; McMahon et al 1997; Hofmann et al 2004; Meltzer 2007). However, the clinical impact of these effects on the nasal mucosa is unclear (Braat et al 1995; Bernstein 2000; Marple et al 2004; Verret and Marple 2005). Perhaps the nasal toxicity of benzalkonium chloride could be neutralized by nasal secretions and corticosteroids actions (Riechelmann et al 2004).

The polysorbates are nonionic surfactants and emulsifying agents used as additives in drugs, food, shampoo, and lotions. Polysorbate 80 reversibly inhibited ciliary beat frequency in cultured human nasal epithelial cells and has been associated with allergy or sensitivity (Shelley et al 1995; Dimova et al 2003).

Carboxymethylcellulose is a thixotropic agent that increases nasal drug concentration, but also confers viscosity to INS solution, which is one of the reasons why the suspension must be shaken before use (Meltzer 2007). It exerts a drying effect on the nasal mucosa that may contribute to the incidence of epistaxis and it also has been involved in rare cases of allergic anaphylactic reactions (Patterson et al 1995; Oppliger et al 2004).

Sensory attributes are an important factor in patient preference and adherence to INS treatment. Patients consider several sensory attributes during INS therapy: aftertaste, taste, smell, run out of nose, throat rundown (drip down), irritation, and urge to sneeze (Mahadevia et al 2004; Meltzer et al 2005; Meltzer 2007); sensation of moisture and soothing have been reported as good attributes. A study showed that benzalkonium chloride has a bitter taste that can be unpleasant (Mahadevia et al 2004).

The FF delivery device is an easy-to-use aqueous pump spray that presents low risk for nasal tissue damage and with a new trigger mechanism that minimizes potential variation in the dose delivered (FDA 2007; Berger et al 2007). The device delivers a low spray volume, which minimizes the amount of drug available to run down the back of the throat or leak out the nose. It is suitable for use in young children aged 2 years and in the elderly.

\section{Clinical trials}

Therapeutic efficacy of fluticasone furonate in AR has been proven by double-blind, placebo-controlled, clinical trials that can be differentiated according to drug dosage, duration of treatment, age of patients, type of rhinitis, and end-points (Table 1).

A dose-ranging study in adolescents and adults with seasonal allergy to mountain cedar pollen established that the $110 \mu \mathrm{g}$ dose provided the optimal benefit-risk ratio. The significant reduction in morning, predose, instantaneous total nasal symptom score (iTNSS) indicated, at least, 24-hour duration of efficacy (Martin et al 2007).

FF was also superior to placebo for reductions in ocular symptoms of adults and adolescents suffering from seasonal and perennial AR (Stuebner 2006; Fokkens et al 2007a; Hampel et al 2007; Kaiser et al 2007; Ratner et al 2007; Vasar et al 2007). The mechanism by which it alleviates allergic conjunctivitis has yet to be fully elucidated. Possible mechanisms include: reduced nasal inflammation resulting in reduced release of inflammatory mediators and, hence, less activation of inflammatory cells in the neighbouring tissues; improved drainage away from the eye down the nasolacrimal duct; and modulation of a naso-ocular neurogenic reflex. It is unlikely that the observed effect results 
Table I Double-blind, placebo-controlled, clinical trials of fluticasone furonate in the treatment of allergic rhinitis

\begin{tabular}{|c|c|c|c|c|}
\hline Clinical trial & Type of rhinitis & Age of patients & Treatment duration & End-points significantly different \\
\hline Martin et al 2007 & \multirow[t]{3}{*}{ Seasonal (mountain cedar) } & \multirow[t]{3}{*}{ Adults and adolescents } & \multirow[t]{3}{*}{2 weeks } & rTNSS, iTNSS, rTOSS, individual nasal \\
\hline Stanford et al 2007a & & & & symptom scores, RQLQ, NRQLQ \\
\hline Stanford et al 2007b & & & & \\
\hline Kaiser et al 2007 & \multirow[t]{2}{*}{ Seasonal (ragweed) } & \multirow[t]{2}{*}{ Adults and adolescents } & \multirow[t]{2}{*}{2 weeks } & \multirow[t]{2}{*}{ rTNSS, iTNSS, rTOSS, RQLQ } \\
\hline Given et al 2007 & & & & \\
\hline Hampel Jr et al 2007 & \multirow[t]{3}{*}{ Seasonal (mountain cedar) } & \multirow[t]{3}{*}{ Adults and adolescents } & \multirow[t]{3}{*}{2 weeks } & \multirow[t]{3}{*}{ rTNSS, iTNSS, rTOSS, RQLQ } \\
\hline van Bavel et al 2007 & & & & \\
\hline Ratner et al 2007 & & & & \\
\hline Fokkens et al 2007a & \multirow[t]{2}{*}{ Seasonal (grass) } & \multirow[t]{2}{*}{ Adults and adolescents } & \multirow[t]{2}{*}{2 weeks } & \multirow[t]{2}{*}{ rTNSS, iTNSS, rTOSS, RQLQ } \\
\hline Fokkens et al 2007b & & & & \\
\hline Meltzer et al 2007a & \multirow[t]{2}{*}{ Seasonal } & \multirow[t]{2}{*}{ Children } & \multirow[t]{2}{*}{2 weeks } & \multirow[t]{2}{*}{ rTNSS, iTNSS } \\
\hline Meltzer et al 2007b & & & & \\
\hline Nathan et al 2007 & Perennial & Adults and adolescents & 4 weeks & rTNSS, iTNSS \\
\hline Vasar et al 2007 & Perennial & Adults and adolescents & 6 weeks & rTNSS, iTNSS, rTOSS, iTOSS \\
\hline Maspero et al 2007 & Perennial & Children & 4 weeks & rTNSS, iTNSS \\
\hline
\end{tabular}

Instantaneous scores indicated the patients' level of symptoms at the time of recording the score, just prior to taking the next medication' dose, each day, as a measure of 24-h duration of action. Reflective scores were based on the symptoms experienced by the patient during the previous $12 \mathrm{~h}$ (morning and evening, the scores summed and averaged to give the daily reflective score).

Abbreviations: rTNSS, reflective total nasal symptom score; iTNSS, instantaneous total nasal symptom score; rTOSS, reflective total ocular symptom score; iTOSS, instantaneous total ocular symptom score; RQLQ, rhinoconjunctivitis quality of life questionnaire; NRQLQ, nocturnal rhinoconjunctivitis quality of life questionnaire.

from systemic action of $\mathrm{FF}$, since it has a low absolute bioavailability.

Oral antihistamines may be used concomitantly with INSs in patients for whom ocular symptoms are troublesome. However, in a meta-analysis of studies comparing INS with antihistamines, INS treatment was shown to reduce ocular symptoms as effectively as oral antihistamines (Weiner et al 1998).

\section{Safety and tolerability}

The severe adverse effects of chronic therapy with systemic corticosteroids are well documented. INS, at recommended doses, are generally not associated with long-term, clinically significant, or irreversible adverse effects. However, many physicians and patients are still concerned about the potential adverse effects of these drugs and these feelings can reduce medication adherence, which is one of the biggest challenges that physicians tackle on a daily basis. If the health care provider can effectively communicate and convince the patient of the benefit/risk ratio of steroids, patient outcomes can be improved (Rao and Apter 2005).

In a pooled analysis of clinical trials, the overall incidence of adverse events with intranasal fluticasone furoate was similar to that with placebo, as was rate of withdrawal from therapy. The most common adverse events (incidence $>1 \%$ in adolescents/adults or $>3 \%$ in children, and with a higher frequency than placebo) were: headache, epistaxis, nasopharyngitis, pyrexia, pharyngolaryngeal pain, nasal ulceration, cough, and back pain (FDA 2007).
Treatment of adults and adolescents with FF for the long term (12 months) was likewise well tolerated, with no unusual or unexpected events. Epistaxis was the only adverse event occurring more frequently and with more severity among FF recipients (FDA 2007; Rosenblut et al 2007). There was no evidence during long-term therapy of adverse events suggestive of clinically relevant systemic corticosteroid exposure.

There is consistent evidence that INS therapy in children can reduce short-term growth and growth velocity, especially during the first year of treatment. However, studies suggest that usual doses of these drugs do not cause clinically relevant growth suppression or reduced final height in the overall majority of patients (Brand 2001; Gulliver and Eid 2005). INS can reduce growth only after they become available systemically. FF systemic bioavailability is low and it had no effect on lower-leg growth rate assessed by knemometry in children (Gradman et al 2007).

Caution is necessary if co-administered with potent CYP3A4 inhibitors, such as ketoconazole and ritonavir, since the increased exposure to FF may increase the risk of systemic adverse effects (FDA).

There is low potential risk for systemic effects at recommended doses of INS. When higher doses are administered, the physician should weight the benefits against the risks and consider the morbidity of uncontrolled rhinitis. To reduce any potential risk for systemic effects, the lowest effective dose of INS should be used. 


\section{Conclusion}

The role of INS in the treatment of AR is well established. They are proven to be efficacious and are recommended as first-line therapy for individuals with persistent moderate/ severe rhinitis.

Knowledge about INS has increased tremendously over the last decade. Studies have elucidated mechanisms of action, pharmacologic properties, and the clinical impact of these drugs in allergic respiratory diseases. Although the existing ICS are already highly efficient, the introduction of further improved formulations with a better efficacy/safety profile is always desired.

FF nasal spray is a new topical corticosteroid, with enhanced-affinity and a unique side-actuated delivery device, which is effective in improving nasal symptoms of AR. Significant improvement in ocular symptoms and in quality of life was also demonstrated. Its low oral bioavailability and high plasma protein binding minimize systemic adverse effects. A potentially prolonged nasal retention time may further enhance the efficacy of FF, which may allow for a once-daily dosing regimen in adults, adolescents, and children.

FF with high topical potency and low potential for systemic effects is a good candidate for rhinitis treatment. As expected for all new drugs, long-term safety and efficacy studies are required, which can establish the potential modification of AR course.

\section{References}

Adams N, Lasserson TJ, Cates CJ, et al. 2007. Fluticasone versus beclomethasone or budesonide for chronic asthma in adults and children. Cochrane Database Syst Rev, 4:CD002310.

Al Sayyad JJ, Fedorowicz Z, Alhashimi D, et al. 2007. Topical nasal steroids for intermittent and persistent alergic rhinitis in children. Cochrane Database Syst Rev, 1:CD003163.

Allen A, Down G, Newlands A, et al. 2007. Tolerability, safety, pharmacokinetics and bioavailability of the novel intranasal corticosteroid fluticasone furoate in healthy subjects [abstract no. P210]. Ann Allergy Asthma Immunol, 98:A89.

Antonicelli L, Micucci C, Voltolini S, et al. 2007. Relationship between ARIA classification and drug treatment in allergic rhinitis and asthma. Allergy, 62:1064-70.

Berger W, Godfrey JW, Grant AC, et al. 2007. Fluticasone furoate (FF) nasal spray: development of a next-generation delivery system for allergic rhinitis [abstract no. 907]. J Allergy Clin Immunol, 119:S231.

Bernstein IL. 2000. Is the use of benzalkonium chloride as a preservative for nasal formulations a safety concern? A cautinary note based on compromised mucociliary transport. J Allergy Clin Immunol, 105:39-44.

Biggadike K, Bledsoe R, Hassell A, et al. 2007. Fluticasone furoate (FF): interactions with the glucocorticoid receptor [abstract no. P219]. Ann Allergy Asthma Immunol, 98:A91-2.

Bousquet J, Van Cauwenberge P, Khaltaev N. 2001. ARIA Workshop Group. Allergic rhinitis and its impact on asthma. J Allergy Clin Immunol, 108:S1-333.
Braat J, Ainge G, Bowles JA, et al. 1995. The lack of effect of benzalkonium chloride on the cilia of the nasal mucosa in patients with perennial allergic rhinitis: a combined functional, light, scanning and transmission electron microscopy study. Clin Exp Allergy, 25:957-65.

Brand PLP. 2001. Inhaled corticosteroids reduce growth. Or do they? Eur Respir J, 17:287-94.

Corren J. 1999. Intranasal corticosteroids for allergic rhinitis: How do different agents compare? J Allergy Clin Immunol, 104:S144-9.

Craig TJ, Teets S, Lehman EB, et al. 1998. Nasal congestion secondary to allergic rhinitis as a cause of sleep disturbance and daytime fatigue and the response to topical nasal corticosteroids. J Allergy Clin Immunol, 101:633-7.

Crystal-Peters J, Crown WH, Goetzel RZ, et al. 2000. The cost of productivity losses associated with allergic rhinitis. Am J Manag Care, 6:373-8.

Crystal-Peters J, Neslusan C, Crown WH, et al. 2002. Treating allergic rhinitis in patients with comorbid asthma: The risk of asthma-related hospitalizations and emergency department visits. J Allergy Clin Immunol, 109:57-62.

Dimova S, Mugabowindekwe R, Willems T, et al. 2003. Safetyassessment of 3-methoxyquercetin as an anthirhinoviral compund for nasal application: effect on ciliary beat frequency. Int $J$ Pharm, 263:95-103.

English AF, Neate MS, Quint DJ, et al. 1994. Biological activities of some corticosteroids used in asthma. Am J Respir Crit Care Med, 149:A212.

FDA. Veramyst ${ }^{\mathrm{TM}}$ (fluticasone furoate) nasal spray: US prescribing information [online]. Accessed 2007, Dec 17. URL: http://www.fda. gov/cder/

Fokkens WJ, Jogi R, Reinartz S, et al. 2007a. Once daily fluticasone furoate nasal spray is effective in seasonal allergic rhinitis caused by grass pollen. Allergy, 62:1078-84.

Fokkens W, Joggi R, Sidorenko I, et al. 2007b. Fluticasone furoate nasal spray (FFNS) 110 mcg once-daily is effective in seasonal allergic rhinitis (SAR) caused by grass pollen [abstract no. 352]. XXVI Congress of the European Academy of Allergology and Clinical Immunology Jun 9-13, 2007. Göteborg.

Given J, Toler T, Ellsworth A, et al. 2007. Once-daily fluticasone furoate nasal spray (FFNS) $110 \mathrm{mcg}$ improves quality of life (QoL) in subjects with seasonal allergic rhinitis (SAR) during the ragweed season [abstract no. 1188]. J Allergy Clin Immunol, 119:S304.

GlaxoSmithKline.Veramyst ${ }^{\mathrm{TM}}$. Accessed 2007, Dec 17. URL: http://www. gsk.com/

Gradman J, Caldwell M, Wolthers O. 2007. Knemometric assessment of short-term lower-leg growth in children with allergic rhinitis (AR) treated with fluticasone furoate (FF) nasal spray [abstract no. 1187]. $J$ Allergy Clin Immunol, 119: S304.

Gulliver T, Eid N. 2005. Effects of glucocorticoids on the hypothalamicpituitary-adrenal axis in children and adults. Immunol Allergy Clin $\mathrm{N}$ Am, 25:541-55.

Hampel Jr FC, Jacobs R, Martin B, et al. 2007. Once-daily fluticasone furoate nasal spray (FF) provides 24-hour symptom relief in subjects with seasonal allergic rhinitis (SAR) caused by mountain cedar pollen [abstract no. 1190]. J Allergy Clin Immunol, 119:S304-5.

Hofmann T, Gugatschga M, Koidl B, et al. 2004. Influence of preservatives and topical steroids on ciliary beat frequency in vitro. Arch Otolaryngol Head Neck Surg, 130:440-5.

Hübner M, Hochhaus G, Derendorf H. 2005. Comparative pharmacology, bioavailability, pharmacokinetics, and pharmacodynamics of inhaled glucocorticosteroids. Immunol Allergy Clin N Am, 25:469-88.

Hughes S, Shardlow P, Rousell V, et al. 2007. Disposition and metabolism of a novel enhanced affinity glucocorticoid, $\left[{ }^{14} \mathrm{C}\right]$-fluticasone furoate (FF) after oral and intravenous (IV) administration in healthy male subjects [abstract no. P216]. Ann Allergy Asthma Immunol, 98:A90-1.

International Consensus Report on the diagnosis and management of rhinitis. 1994. International Rhinitis Management Working Group. Allergy, 49:1-34. 
Juniper EF, Guyatt GH, Archer B, et al. 1993. Aqueous beclomethasone dipropionate in the treatment of ragweed pollen-induced rhinitis: further exploration of "as needed" use. J Allergy Clin Immunol, 92:66-72.

Kaiser HB, Naclerio RM, Given J, et al. 2007. Fluticasone furoate nasal spray: a single treatment option for the symptoms of seasonal allergic rhinitis. J Allergy Clin Immunol, 119:1430-7.

Leynaert B, Neukirch C, Liard R, et al. 2000a. Quality of life in allergic rhinitis and asthma: a population based study of young adults. Am J Respir Crit Care Med, 162:1391-6.

Leynaert B, Neukirch F, Demoly P, et al. 2000b. Epidemiological evidence for asthma and rhinitis comorbidity. J Allergy Clin Immunol, 106:S201-5.

Linneberg A, Henrik Nielsen N, Frolund L, et al. 2002. Copenhagen Allergy Study. The link between allergic rhinitis and allergic asthma: a prospective population-based study. The Copenhagen Allergy Study. Allergy, 57:1048-52.

Mahadevia PJ, Shah S, Leibman C, et al. 2004. Patient preferences for sensory attributes of intranasal corticosteroids and willingness to adhere to prescribed therapy for allergic rhinitis: a conjoint analysis. Ann Allergy Asthma Immunol, 93:345-50.

Marple B, Rolanf P, Benninger M. 2004. Safety review of benzalkonium chloride used as a preservative in intranasal solutions: an overview of conflicting data and opinions. Otolaryngol Head Neck Surg, 130:131-41.

Martin BG, Ratner PH, Hampel FC, et al. 2007. Optimal dose selection of fluticasone furoate nasal spray for the treatment of seasonal allergic rhinitis in adults and adolescents. Allergy Asthma Proc, 28:216-25.

Maspero JF, Rosenblut A, Finn Jr A, et al. 2007. Once-daily fluticasone furoate nasal spray (FF) is safe and effective in the long-term treatment of perennial allergic rhinitis (PAR) in children ages 2 to 11 years [abstract no. 1189]. J Allergy Clin Immunol, 119:S304.

McCormack PL, Scott LJ. 2007. Fluticasone furoate: intranasal use in allergic rhinitis. Drugs, 67:1905-15.

McKenzie AW. 1962. Percutaneous absorption of steroids. Arch Dermatol, 86:611-4.

McMahon C, Darby Y, Ryan R, et al. 1997. Immediate and short-term effects of benzalkonium chloride on the human nasal mucosa in vivo. Clin Otolaryngol Allied Sci, 22:318-22.

Meltzer EO, Bardelas J, Goldsobel A, et al. 2005. A preference evaluation study comparing the sensory attributes of mometasone furoate and fluticasone propionate nasal sprays by patients with allergic rhinitis. Treat Respir Med, 4:289-96.

Meltzer EO. 2007. Formulation considerations of intranasal corticosteroids for the treatment of allergic rhinitis. Ann Allergy Asthma Immunol, 98:12-21.

Meltzer EO, Tripathy I, Lee J, et al. 2007a. Once-daily fluticasone furoate nasal spray (FF) provides 24-hour relief of the nasal symptoms of seasonal allergic rhinitis (SAR) in children ages 2-11 years [abstract no. 1193]. J Allergy Clin Immunol, 119:S305.

Meltzer EO, Lee J, Tripathy I, et al. 2007b. Study to assess the efficacy and safety of two doses of fluticasone furoate nasal spray in children with seasonal allergic rhinitis [abstract no. 343]. XXVI Congress of the European Academy of Allergology and Clinical Immunology, 2007, Jun 9-13. Göteborg.

Nathan R, Berger W, Yang W, et al. 2007. Once daily fluticasone furoate nasal spray (FFNS), a novel enhanced affinity steroid, provides 24-hour relief for the nasal symptoms of perennial allergic rhinitis (PAR) [abstract no. 254]. J Allergy Clin Immunol, 119:S65.

O'Connell EJ. 2004. The burden of atopy and asthma in children. Allergy, $59: 7-11$

Oppliger R, Hauser C. 2004. Anaphylaxis after injection of corticosteroid preparations-carboxymethylcellulose as a hidden allergen [in German]. $J$ Dtsch Dermatol Ges, 2:928-30.

Pastel D, Ratner P, Clements D, et al. 2007. Lack of efect on hypothalamicpituitary-adrenal (HPA) axis function by once-daily fluticasone furoate nasal spray (FFNS) $110 \mathrm{mcg}$ in adolescents and adults with perennial allergic rhinitis [abstract no. 909]. J Allergy Clin Immunol, 119:S305.
Patterson DL, Yunginger JW, Dunn WF, et al. 1995. Anaohykaxis induced by carboxymethylcellulose component of injectable triamcinolone acetonide suspension (Kenalog). Ann Allergy Asthma Immunol, 74:163-6.

Price D, Bond C, Bouchard J, et al. 2006. International Primary Care Respiratory Group (IPCRG) Guidelines: management of allergic rhinitis. Prim Care Respir J, 15:58-70.

Rao VU, Apter AJ. 2005. Steroid phobia and adherence-problems, solutions, impact on benefit/risk profile. Immunol Allergy Clin N Am, 25:581-95.

Ratner P, Andrews C, van Bavel J, et al. 2007. Once-daily fluticasone furoate nasal spray (FF) effectively treats ocular symptoms of seasonal allergic rhinitis (SAR) caused by mountain cedar pollen [abstract no. 908]. J Allergy Clin Immunol, 119:S231.

Riechelmann H, Deutschle T, Stuhlmiller A, et al. 2004. Nasal toxicity of benzalkonium chloride. Am J Rhinol, 18:291-9.

Rosenblut A, Bardin PG, Muller B, et al. 2007. Long-term safety of fluticasone furoate nasal spray in adults and adolescents with perennial allergic rhinitis. Allergy, 62:1071-7.

RxList. The internet drug index. Veramyst ${ }^{\mathrm{TM}}$. Accessed 2007 Dec 17. URL: http://www.rxlist.com/cgi/generic/veramyst/

Salter M, Biggadike K, Clackers M, et al. 2006. GW685698X - enhanced affinity for the glucocorticoid receptor: cellular and in nvivo pharmacology [abstract no. 781]. 25th Congress of the European Academy of Allergology and Clinical Immunology. 2006, Jun 10-14. Vienna.

Salter M, Biggadike K, Clackers M, et al. 2007. Fluticasone furoate (FF): enhanced cellular and tissue protection with a new selective glucocorticoid agonist [abstract no. P212]. Ann Allergy Asthma Immunol, 98:A89.

Schoenwetter WF, Dupclay LJr, Appajosyula S, et al. 2004. Economic impact and quality-of-life burden of allergic rhinitis. Curr Med Res Opin, 20:305-17.

Shelley WB, Talanin N, Shelley ED. 1995. Polysorbate 80 hypersensitivity. Lancet, 345:1312-13.

Stanford R, Philpot E, Faris M, et al. 2007a. Fluticasone furoate nasal spray once-daily improves quality of life in subjects with seasonal allergic rhinitis (SAR) [abstract no. P214]. Ann Allergy Asthma Immunol, 98:A90.

Stanford R, Philpot E, Faris M, et al. 2007b. Fluticasone furoate nasal spray once-daily improves nocturnal quality of life in subjects with seasonal allergic rhinitis (SAR) [abstract no. P208]. Ann Allergy Asthma Immunol, 98:A88-9.

Steinsvag SK, Bjerknes R, Berg OH. 1996. Effects of topical nasal steroids on human respiratory mucosa and human granulocytes in vitro. Acta Otolaryngol, 116:868-75.

Stuebner P. 2006. Effects of the novel intranasal glucocorticosteroid GW685698 (200 mcg once-daily) on seasonal allergic rhinitis (SAR) symptoms induced in the Vienna challenge chamber model (VCC) [abstract no. 1232]. J Allergy Clin Immunol, 117:S319.

Taramarcaz P, Gibson PG. Intranasal corticosteroids for asthma control in people with coexisting asthma and rhinitis. Cochrane Database Syst Rev 2003. 3: CD003570.

The International Study of Asthma and Allergies I Childhood (ISAAC) Steering committee. 1998. Worldwide variation in prevalence of symptoms of asthma, allergic rhinoconjunctivitis, and atopic eczema: ISAAC. Lancet, 351:1225-32.

Togias A. 2003. Rhinitis and asthma: evidence for respiratory system integration. J Allergy Clin Immunol, 111:1171-83.

Tripathy I, Sterling R, Clements D, et al. 2007. Lack of efect on hypothalamic-pituitary-adrenal (HPA) axis function by once-daily fluticasone furoate nasal spray (FFNS) $110 \mathrm{mcg}$ in children with perennial allergic rhinitis [abstract no. 909]. J Allergy Clin Immunol, 119:S232.

Umland SP, Narhebne DK, Razac BS, et al. 1997. The inhibitory effects of topically active glucocorticoids on IL-4, IL-5, and interferon-[gama] production by cultured primary $\mathrm{CD}^{+}$cells. J Allergy Clin Immunol, 100:511-9.

Upton MN, McConnachie A, Mcsharry C, et al. 2000. Intergeneration 20 year trends in the prevalence of asthma and hay fever in adults: the Midspan family study surveys of parents and offspring. $\mathrm{Br}$ Med J, 321:88-92. 
van Bavel J, Toler T, Ellsworth A, et al. 2007. Once-daily fluticasone furoate nasal spray (FFNS) improves quality of life (QoL) in subjects with seasonal allergic rhinitis (SAR) during the mountatin cedar pollen season [abstract no. 903]. J Allergy Clin Immunol, 119:S230.

van Cauwenberge P, Van Hoecke H, Vandenbulcke L, et al. 2005. Glucocorticosteroids in allergic inflammation: clinical benefits in allergic rhinitis, rhinosinusitis, and otitis media. Immunol Allergy Clin N Am, 25:489-509.

Vasar M, Houle P-A, Douglass JA, et al. 2007. A novel enhanced-affinity corticosteroid, once daily fluticasone furoate nasal spray (FFNS), provides 24-hour relief for the nasal symptoms of perennial allergic rhinitis (PAR) [abstract no. 626]. XXVI Congress of the European Academy of Allergology and Clinical Immunology 2007, Jun 9-13. Göteborg.
Verret DJ, Marple BF. 2005. Effect of topical nasal steroid sprays on nasal mucosa and ciliary function. Curr Opin Otolaryngol Head Neck Surg, 13:14-18.

Weiner JM, Abramson MJ, Puy RM. 1998. Intranasal corticosteroids versus oral $\mathrm{H} 1$ receptor antagonists in allergic rhinitis: systematic review of randomised controlled trials. Br Med J, 317:1624-9.

Yawn BP, Yunginger JW, Wollan PC, et al. 1999. Allergic rhinitis in Rochester, Minnesota residents with asthma: frequency and impact on health care charges. J Allergy Clin Immunol, 103:54-9. 